\title{
Curvularia curculiginis causes leaf spot and blight on Curculigo capitulata in China
}

\author{
Hai Feng Liu ${ }^{1} \cdot$ Qing Chen Zha ${ }^{1} \cdot$ Tian Ci Huang ${ }^{2} \cdot$ Cheng Xin Huang ${ }^{1} \cdot$ Dong Fang Pei ${ }^{1}$. Quan Ke Liu ${ }^{3}$ - Jian Xin Deng ${ }^{1}$
}

Received: 24 January 2019 / Accepted: 19 May 2019/Published online: 25 May 2019

(C) Australasian Plant Pathology Society Inc. 2019

\begin{abstract}
Leaf spot and blight on Curculigo capitulata was found in Fair Lake Botanical Garden, Shenzhen, Guangdong, China in 2018. Curvularia curculiginis, identified by morphology, was associated with the symptoms. Molecular barcodes from the internal transcribed spacer region of rDNA (ITS), and partial fragments of glyceraldehyde-3-phosphate dehydrogenase (gapdh) and translation elongation factor 1- $\alpha$ (tefl) genes were provided. Pathogenicity tests showed for the first time that $C$. curculiginis was pathogenic on leaves of its host.
\end{abstract}

Keywords Amaryllidaceae $\cdot$ Curvularia $\cdot$ Morphology $\cdot$ Phylogenetic analysis $\cdot$ Pathogenicity

Curculigo capitulata, belonging to the family Amaryllidaceae, has a long history of medical use in China and India (Kirtikar and Basu 1935; Nie et al. 2013). Curvularia curculiginis, Pseudocercospora curculiginis and Puccinia curculiginis were associated with Curculigo capitulata according to U.S. National Fungus Collections Fungus-Host Database (https://nt.ars-grin.gov/ fungaldatabases/fungushost/fungushost.cfm) and previous publications (Arthur and Cummins 1936; Guo and Liu 1992; Zhang and Zhang 2003). Among them, C. curculiginis was described as a new species based on morphology by Zhang and Zhang (2003). The species was collected from living leaves of Curculigo capitulata, in Nanning city, Guangxi province, China. However, there is no mention about its pathogenicity (Zhang and Zhang 2003; Zhang and Sun 2010). In August 2018, leaf spot and blight of Curculigo capitulata was observed in Shenzhen Fair Lake Botanical Garden, Shenzhen city, Guangdong province, China. Many small to large, round or irregular brown necrotic spots surrounded with chlorotic halos occurred throughout the

Jian Xin Deng

djxin555@yangtzeu.edu.cn

1 Department of Plant Protection, College of Agriculture, Yangtze University, Jingzhou 434025, China

2 Department of Bioengineering, College of Life Sciences, Yangtze University, Jingzhou 434025, China

3 General Station of Plant Protection of Hubei Province, Wuhan 430070, China leaves. The apices were normally wilted. In serious cases, leaves were entirely withered (Fig. 1a-b).

Diseased leaf samples were cut into small pieces, and then placed into Petri-dishes with moist filter papers. After incubation at $25^{\circ} \mathrm{C}$, conidia similar to Curvularia spp. were encountered from tissues. To obtain pure cultures, conidia were singly picked using sterile glass needles and transferred onto potato dextrose agar (PDA) according to the method of Luo et al. (2018). Strains were deposited in the Culture Collection of Yangtze University (YZU) in Jingzhou, China. The colonies of those strains were identical to each other. Hence, one isolate YZU 181230 was selected for further study to identify the species. The colony characteristics were determined on PDA and conidial morphology was studied on water agar (WA) incubated at $25{ }^{\circ} \mathrm{C}$ in darkness for 7 days. Conidia were mounted in sterile distilled water and examined under a Nikon ECLIPSE Ni-U microscope system (Nikon, Japan). Colony on PDA was velutinous, margin fimbriate, pale smoke grey to greyish sepia, buffer to purplish grey, $77-78 \mathrm{~mm}$ diam. (Fig. 2a). On WA, conidiophores were straight or flexuous, normally $60-133 \mu \mathrm{m}$ long, 4-6 $\mu \mathrm{m}$ wide. Conidia were ellipsoidal, obovoid or obclavate, $23-47 \times 13-23 \mu \mathrm{m}$ in size with 3 transverse septa among which the middle one was the thickest septum (Fig. 2b-d). Morphologically, the isolate was identical to C. curculiginis with the holotype of HSAUP 992140 (Zhang and Zhang 2003; Zhang and Sun 2010).

Genomic DNA of the strain YZU 181230 was extracted from fresh mycelia grown on PDA using the method of Cenis (1992). Three gene regions were amplified, namely the internal transcribed spacer region of rDNA (ITS), glyceraldehyde- 
Fig. 1 Symptoms caused by Curvularia curculiginis on Curculigo capitulata: $\mathbf{a - b}$ leaf spot and blight in field, c-d necrotic spots induced by mycelia plugs and spore suspension, respectively, on wounded (left) and unwound (right) of living leaves after 10 days at $25^{\circ} \mathrm{C}$ $(\mathrm{ck}=$ control $)$
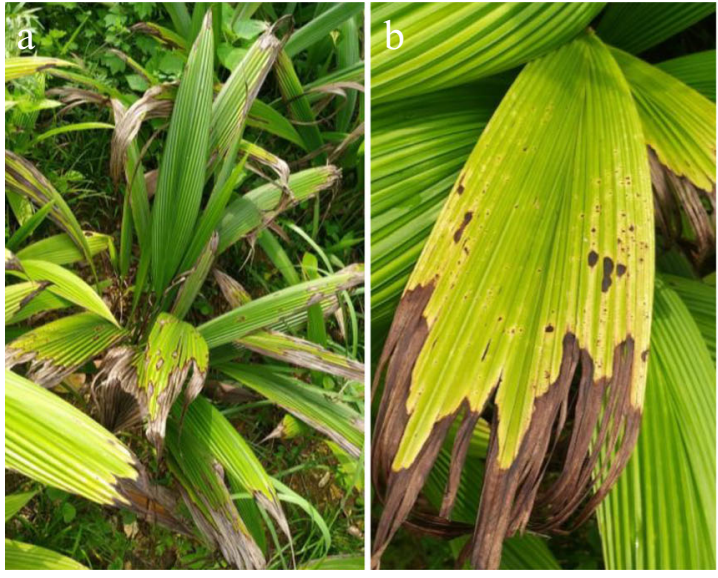

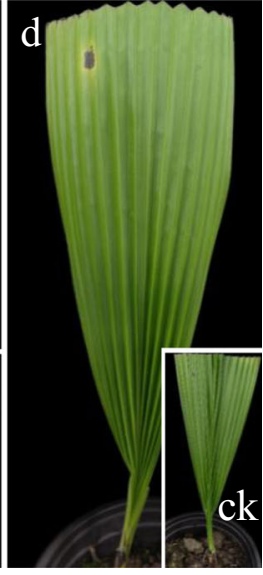

3-phosphate dehydrogenase (gapdh) and translation elongation factor 1- $\alpha$ (tefl) using BIO-RAD T100 $10{ }^{\mathrm{TM}}$ Thermal Cycler (BioRad, CA, USA). The primer pairs were selected according to Tan et al. (2014): ITS5/ITS4 (White et al. 1990) for ITS, gpd1/gpd2 (Berbee et al. 1999) for gapdh, EF1983/EF12218R (Schoch et al. 2009) for tef1. The PCRs were amplified in $25 \mu \mathrm{L}$ of reaction mixture including $12.5 \mu \mathrm{L} 2 \times$ Taq PCR
Starmix (Genstar, Beijing, China), $1.25 \mu \mathrm{L}$ of each primer, $2 \mu \mathrm{L}$ template DNA, and $8 \mu \mathrm{L}$ sterile distilled water. Successfully amplified products were sequenced by BGI (Beijing, China) with both primers. The obtained sequences were deposited in GenBank with accession numbers of MK507796 (ITS), MK507794 (gapdh) and MK507795 (tef1). A maximum likelihood tree was constructed using
Fig. 2 Morphology of Curvularia curculiginis YZU 181230: a colony on PDA for 7 days at $25^{\circ} \mathrm{C}$, b sporulation patterns on WA at $25^{\circ} \mathrm{C}, \mathbf{c}-\mathbf{d}$ conidia on media, e sporulation patterns from leaf symptoms at $25^{\circ} \mathrm{C}, \mathbf{f}$ conidia from host. Scale bars: $b$, $\mathrm{e}=40 \mu \mathrm{m}, \mathrm{c}, \mathrm{d}, \mathrm{f}=20 \mu \mathrm{m}$
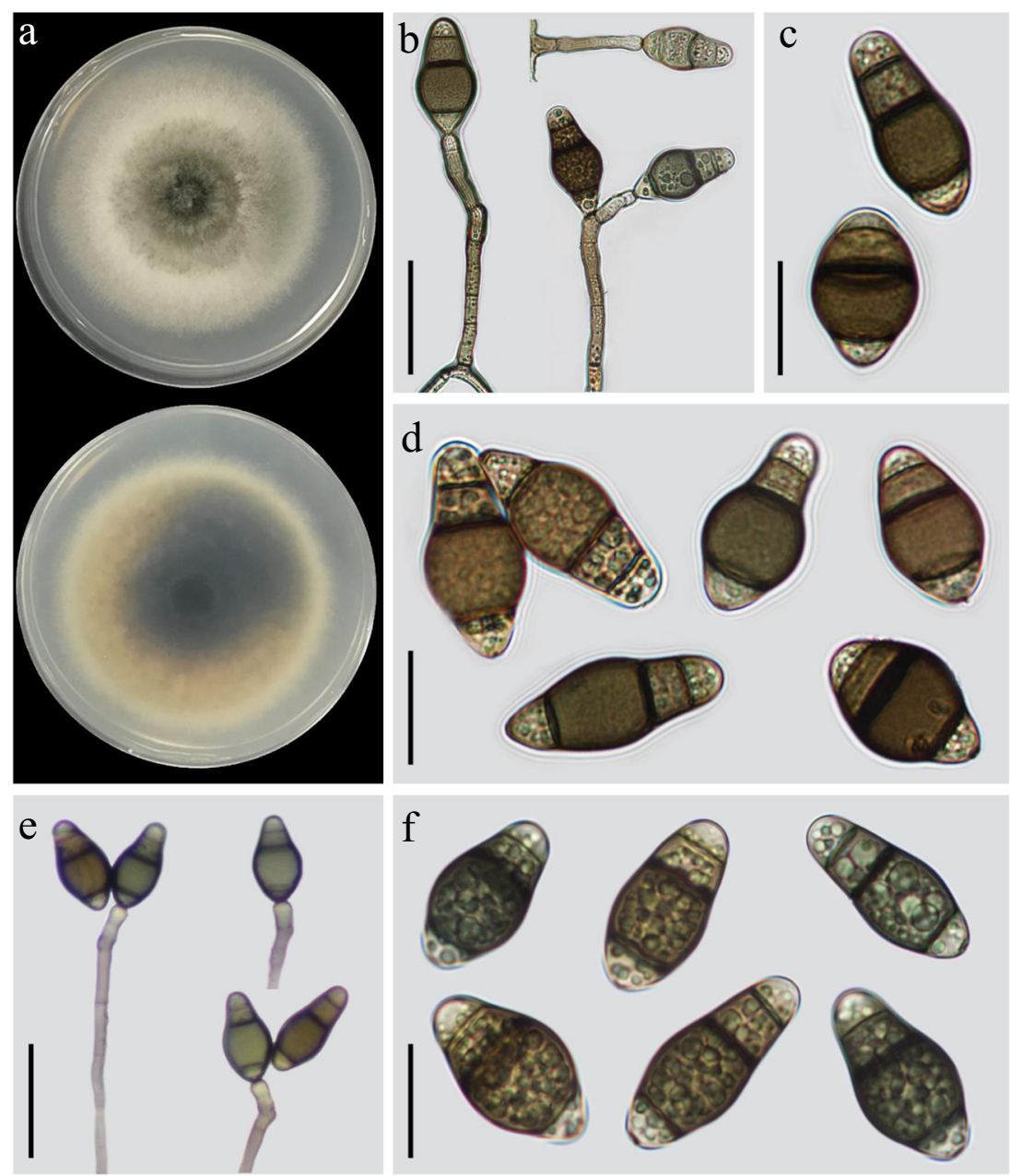
representative isolates of 24 relevant species (Tan et al. 2018) to determine the phylogenetic relationship (Fig. 3). Each gene sequence was aligned and concatenated for a combined analysis using MEGA v7.0 (Kumar et al. 2016). The maximum likelihood analysis with 1000 bootstrap replicates was performed in RAxML program (Stamatakis et al. 2008) using the GTRCAT model of nucleotide substitution. In the resulting phylogram, the present isolate was demonstrated as a separate species of Curvularia which supported the morphological results of $C$. curculiginis (Zhang and Zhang 2003). Its closest phylogenetic species is $C$. reesii collected from air in Australia (Tan et al. 2018).

Morphologically, conidia of C. curculiginis were larger than those of $C$. reesii, which were (28-) 31-35 $(-39) \times(10-) 12-13(-14) \mu \mathrm{m}$ in size (Tan et al. 2018). Conidia of $C$. curculiginis were similar to C. oryzae (24$40 \times 12-22 \mu \mathrm{m})$ and C. tuberculata $(23-52 \times 13-20 \mu \mathrm{m})$ in size (Sivanesan 1987), but it was different from C. oryzae in having a thick middle septum of conidia and distinct from C. tuberculata without verruculose ornamented cell walls (Zhang and Sun 2010).
Pathogenicity of the isolate YZU 181230 was determined on leaves of potted Curculigo capitulata. The leaves (over $20 \mathrm{~cm}$ high) were sprayed with $70 \%$ ethanol prior to inoculation. Mycelia disks ( $3 \mathrm{~mm}$ in diam.) and $20 \mu \mathrm{L}$ spore suspension $\left(10^{5}\right.$ spores per $\left.\mathrm{mL}\right)$ were placed onto needle-wounded and unwounded areas on leaves (Fig. 1). Controls were treated with pure PDA disk and distilled water. The inoculated plants were placed in a greenhouse with a $12 \mathrm{~h}$ fluorescent light period around $25{ }^{\circ} \mathrm{C}$. Large necrotic spots (around $12 \times$ $45 \mathrm{~mm}$ in size) surrounded with yellow halos were observed on mycelia disc inoculated leaves at 10 days, while the smaller similar symptoms (around $3 \times 10 \mathrm{~mm}$ in size) were induced only on wounded leaves by spore suspension. Controls were symptomless after 10 days.

To examine the morphology of the fungus from host, the fungus was grown from the inoculated tissues using the method as previously described for isolation. Conidia were reisolated and matched to C. curculiginis. At the same time, the sporulation patterns and conidial characteristics were observed (Fig. 2). The conidial morphology on the host was identical to that grown on WA. Only the conidia size was
Fig. 3 Maximum likelihood phylogenetic tree of Curvularia curculiginis generated from the combined dataset of ITS, gapdh and tefl gene sequences. Bootstrap values ( $>70 \%$ ) from 1000 replicates are shown at nodes. The bar indicates the number of substitutions per position

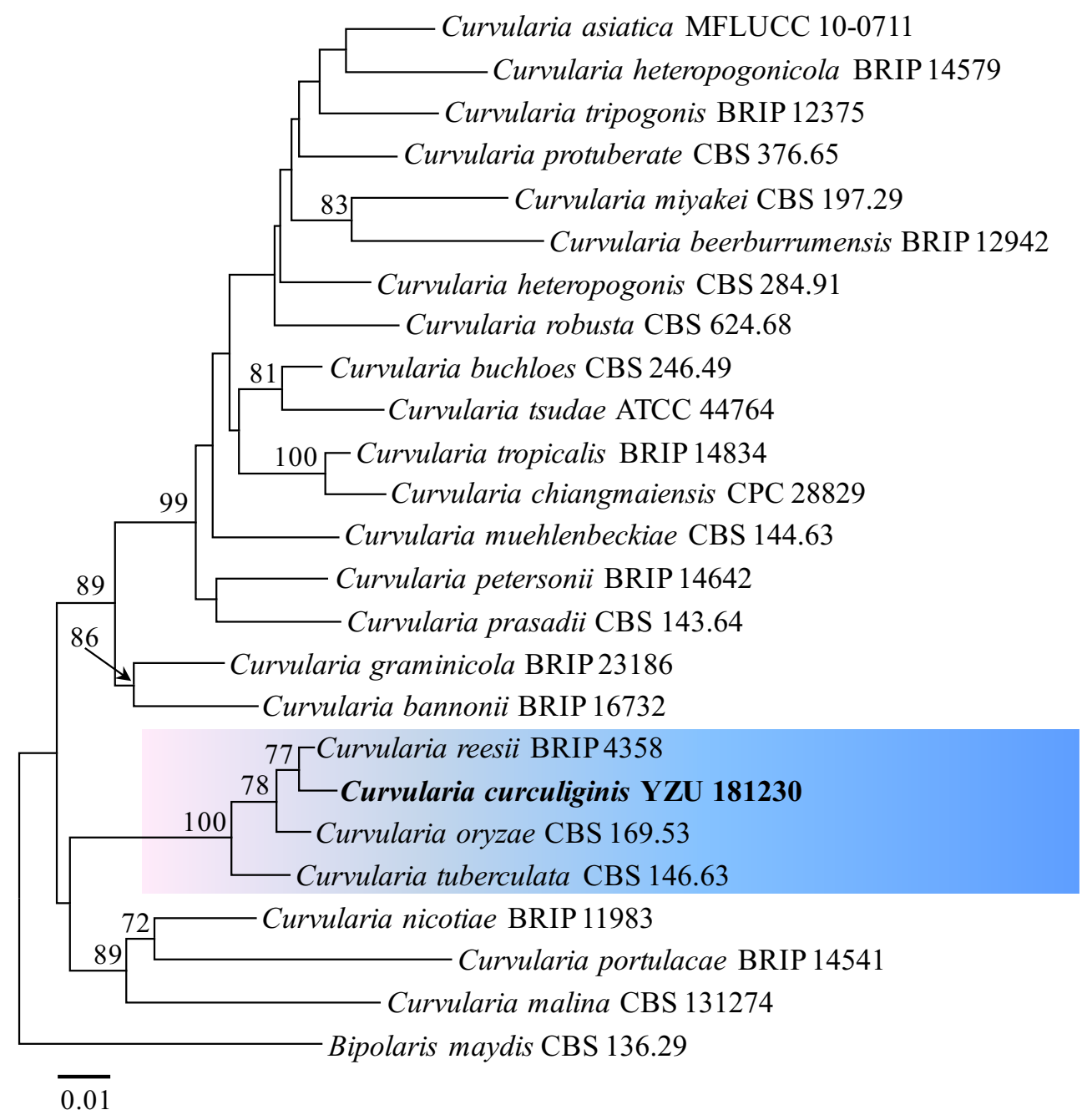


smaller at 28-41 × 13-20 $\mu \mathrm{m}$ (Fig. 2e-f). The results indicated that Curvularia curculiginis is a causal agent to induce leaf spot and blight on Curculigo capitulata.

We showed the species placement of $C$. curculiginis with a phylogenetic species concept based on three gene regions. This supported the morphological taxonomy described by Zhang and Zhang (2003). We further showed that $C$. curculiginis is a pathogen of Curculigo capitulata.

Acknowledgements This study was supported by the National Natural Science Foundation of China (31400014), and the Young Scientist Foundation of Yangtze University (2016cqr08).

\section{References}

Arthur JC, Cummins GB (1936) Philippine rusts in the Clemens collection 1923-1926. I. Philipp J Sci 59:437-449

Berbee ML, Pirseyedi M, Hubbard S (1999) Cochliobolus phylogenetics and the origin of known, highly virulent pathogens, inferred from ITS and glyceraldehyde-3-phosphate dehydrogenase gene sequences. Mycologia 91:964-977

Cenis J (1992) Rapid extraction of fungal DNA for PCR amplification. Nucleic Acids Res 20:2380

Guo YL, Liu XJ (1992) Studies on the genus Pseudocercospora in China VI. Mycosystema 5:99-108

Kirtikar KR, Basu BD (1935) Indian medicinal plants. Allahabad 2:2469
Kumar S, Stecher G, Tamura K (2016) MEGA7: molecular evolutionary genetics analysis version 7.0 for bigger datasets. Mol Biol Evol 33: 1870-1874

Luo H, Tao YQ, Fan XY, Oh SK, Lu HX, Deng JX (2018) Identification and characterization of Alternaria iridiaustralis causing leaf spot on Iris ensata in China. Mycobiology 46:168-171

Nie Y, Dong X, He YJ, Yuan TT, Han T, Rahman K, Qin L, Zhang QY (2013) Medicinal plants of genus Curculigo: traditional uses and a phytochemical and ethnopharmacological review. J Ethnopharmacol 147:547-563

Schoch CL, Crous PW, Groenewald JZ, Boehm E, Burgess TI, de Gruyter K, de Hoog G, Dixon L, Grube M, Gueidan C (2009) A class-wide phylogenetic assessment of Dothideomycetes. Stud Mycol 64:1-15

Sivanesan A (1987) Graminicolous species of Bipolaris, Curvularia, Drechslera, Exserohilum and their teleomorphs. Mycol Pap 158: $1-261$

Stamatakis A, Hoover P, Rougemont J (2008) A rapid bootstrap algorithm for the RAxML web servers. Sys Bio 57:758-771

Tan YP, Madrid H, Crous PW, Shivas RG (2014) Johnalcornia gen. et. comb. nov., and nine new combinations in Curvularia based on molecular phylogenetic analysis. Australas Plant Pathol 43:589-603

Tan YP, Crous PW, Shivas RG (2018) Cryptic species of Curvularia in the culture collection of the Queensland plant pathology herbarium. Mycokeys 35:1-25

White TJ, Bruns T, Lee S, Taylor J (1990) Amplification and direct sequencing of fungal ribosomal RNA genes for phylogenetics. In: Innis MA, Gelfand DH, Shinsky JJ, White TJ (eds) PCR protocols: a guide to methods and applications. Academic Press, San Diego

Zhang TY, Sun GY (2010) Flora Fungorum Sinicorum, Helminthosporioid Hyphomycetes, vol 30. Beijing, China

Zhang M, Zhang TY (2003) A new species of Curvularia from China. Mycosystema 22:357-358 